Supplement of

\title{
2005-2017 ozone trends and potential benefits of local measures as deduced from air quality measurements in the north of the Barcelona metropolitan area
}

Jordi Massagué et al.

Correspondence to: Jordi Massagué (jordi.massague@idaea.csic.es)

The copyright of individual parts of the supplement might differ from the CC BY 4.0 License. 

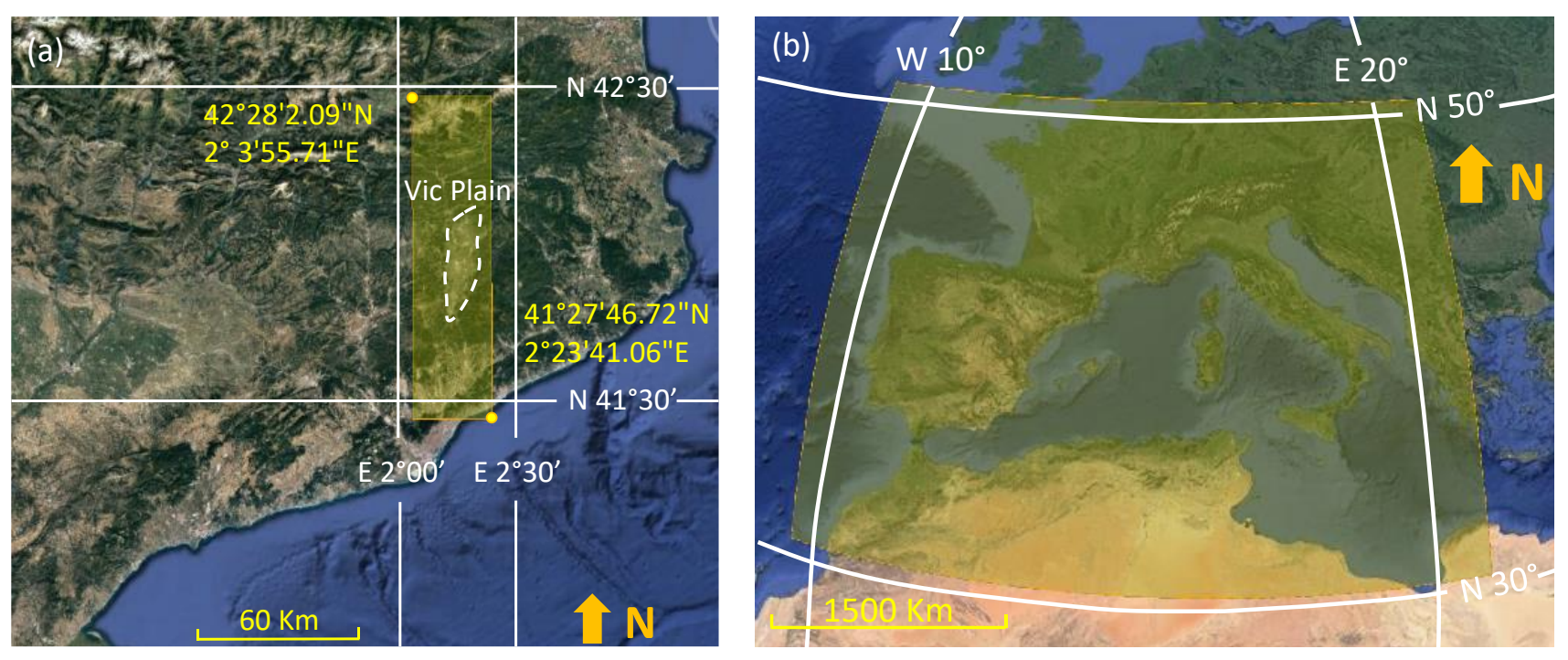

Figure S1. Selected regions for retrieval of OMI Tropospheric Column $\mathrm{NO}_{2}$ in yellow: (a) area along the S-N axis $\left(\sim 3,040 \mathrm{~km}^{2}\right)$ which includes northern Barcelona metropolitan area (BMA), the Vic Plain and an area of the Pre-Pyrenean range to analyze quantitatively the time trends and patterns and (b) across western Europe $\left(\sim 6,514 \times 10^{6} \mathrm{~km}^{2}\right)$ to analyze qualitatively the $\mathrm{NO}_{2}$ spatial patterns in the two scenarios considered (when the amount of $\mathrm{O}_{3}$ in the Vic Plain is high and when it is low).
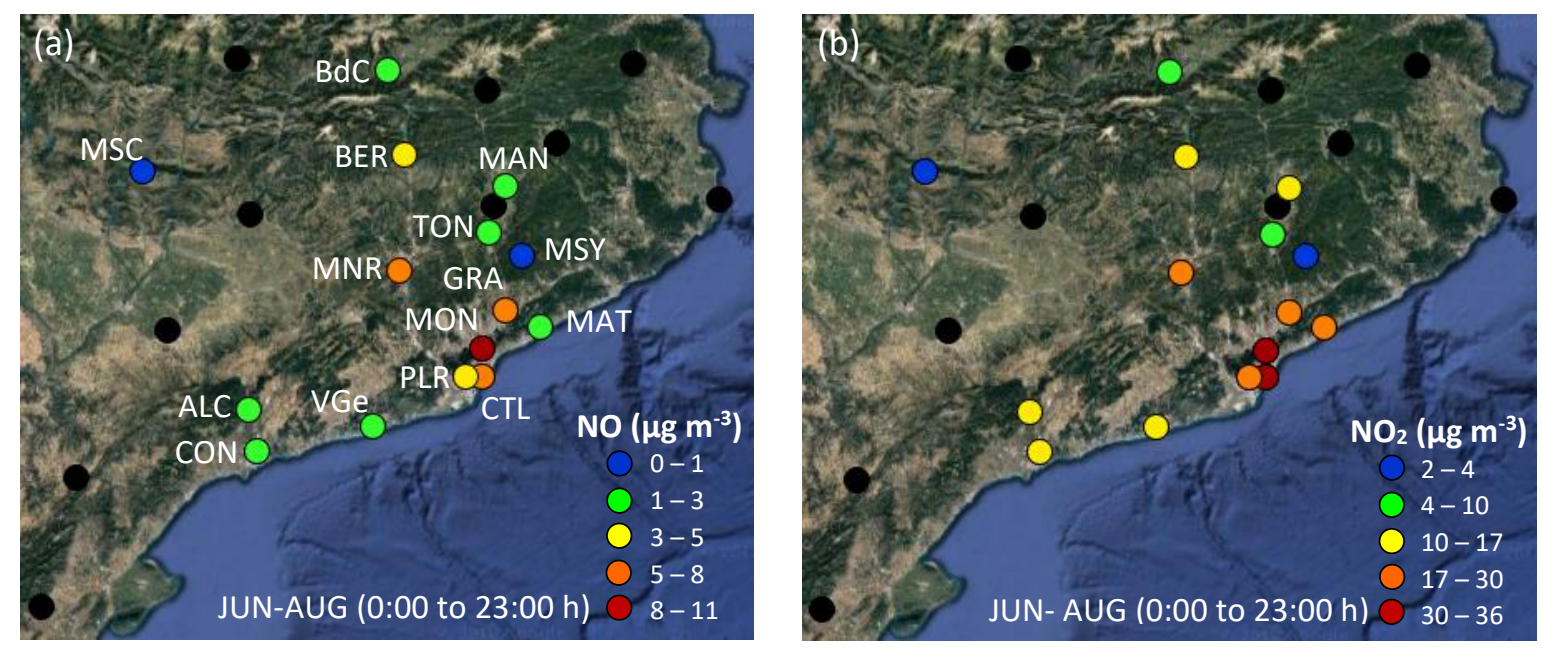

Figure S2. (a) Spatial variability of mean June-August $\mathrm{NO}$ (a) and $\mathrm{NO}_{2}$ (b) concentrations observed in selected AQ sites. Data from Ciutadella (CTL), Palau Reial (PLR), Montcada (MON), Granollers (GRA), Montseny (MSY), Manlleu (MAN), Tona (TON), Montsec (MSC), Bellver de Cerdanya (BdC), Berga (BER), Mataró (MAT), Manresa (MNR), Vilanova i la Geltrú (VGe), Constantí (CON) and Alcover (ALC) air quality monitoring stations. 

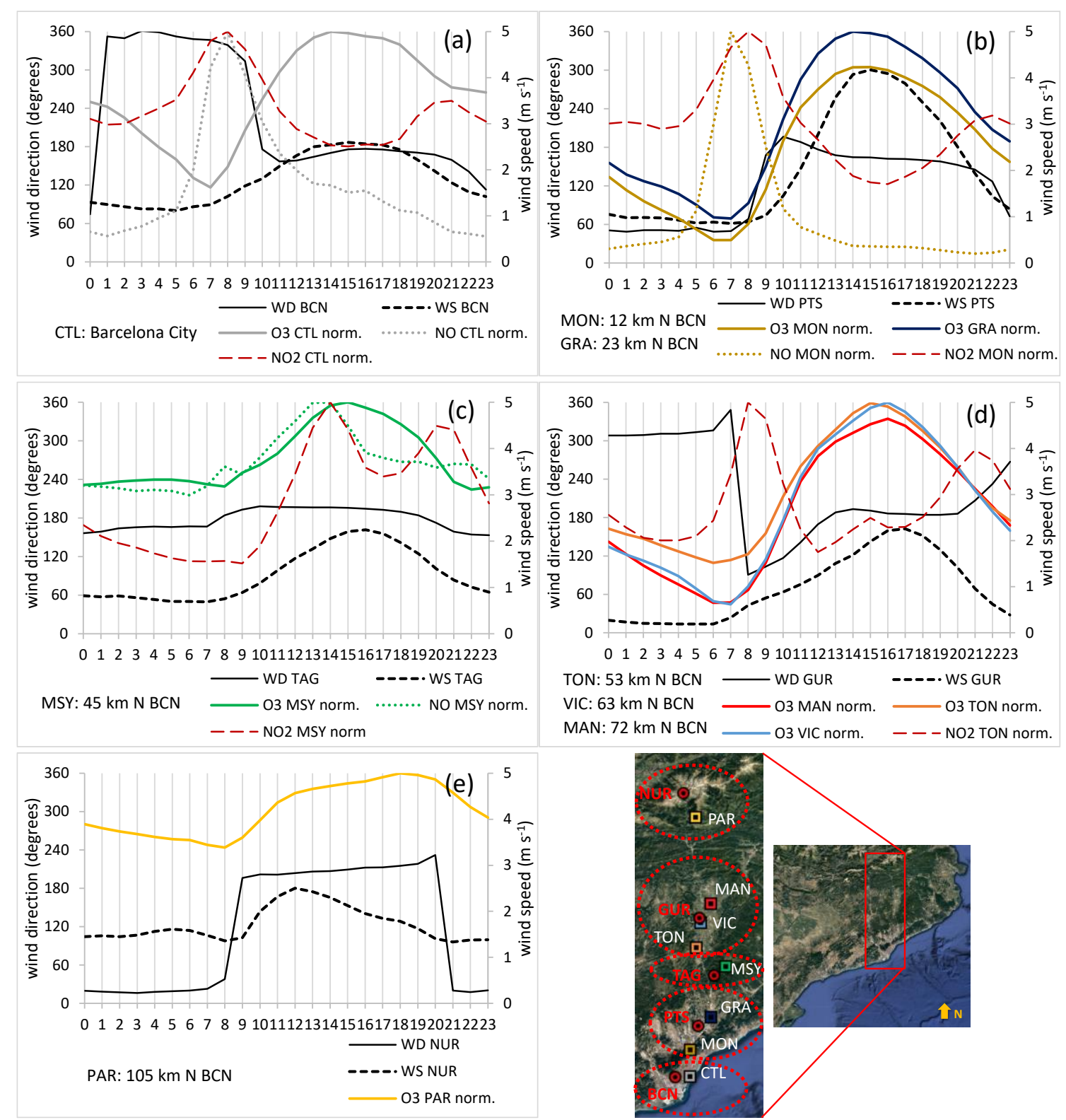

Figure S3. Normalized $\mathrm{O}_{3}, \mathrm{NO}$ and $\mathrm{NO}_{2}$ cycles and wind patterns for July (wind coming direction in the left vertical axis and wind speed in the right vertical axis). Pollutants' concentrations $\left(\mathrm{O}_{3}, \mathrm{NO}\right.$ and $\left.\mathrm{NO}_{2}\right)$ are normalized to the highest average value to emphasize the shape of the cycles, in the case of more than one $\mathrm{O}_{3}$ cycle in a graph (b) and (d) plots, the $\mathrm{O}_{3}$ concentrations are normalized to the highest $\mathrm{O}_{3}$ values of the site that measured them. July average wind speeds and directions data come from meteorological stations located near the corresponding AQ sites: (a) AQ CTL monitoring site with meteorological BCN; (b) AQ MON and GRA monitoring sites with meteorological PTS; (c) AQ MSY monitoring site with meteorological TAG; (d) AQ TON, VIC and MAN monitoring sites with meteorological GUR; (e) AQ PAR monitoring site with meteorological NUR. The map shows the location of AQ monitoring sites (white codes; squares) and close meteorological sites (red codes; circles) grouped by pointed circles. AQ data are from monitoring sites along the $\mathrm{S}-\mathrm{N}$ axis. In general, the highest $\mathrm{O}_{3}$ levels occur when the wind blows from the south (location of the Barcelona metropolitan area, BMA) at its maximum velocity, confirming the clear influence of the BMA plume transport. 